\title{
Consequences of Insurance Denials Among U.S. Patients Prescribed Repository Corticotropin Injection for Acute Exacerbations of Multiple Sclerosis
}

\author{
J. Bradford Rice · Mary P. Panaccio · Alan White • Mark Simes • \\ Emma Billmyer · Nathaniel Downes · John Niewoehner • \\ George J. Wan
}

Received: August 31, 2020 / Accepted: October 1, 2020 / Published online: November 10, 2020

(C) The Author(s) 2020

\section{ABSTRACT}

Introduction: Repository corticotropin injection (RCI; Acthar ${ }^{\circledR}$ Gel) is indicated for the treatment of acute exacerbations of multiple sclerosis (MS) in adults. Despite the well-documented clinical and economic benefits of RCI, many patients are denied use of the therapy by third-party payers. This study aims to understand the demographic and clinical characteristics of MS relapse patients who received a prescription for RCI from their physicians and then were either approved or denied treatment by their insurers. The study compares measurable clinical outcomes and healthcare resource utilization (HCRU) between approved and denied cohorts.

Methods: A retrospective analysis of adults experiencing MS relapse from January 2015 to December 2018 was conducted using a deidentified open-source claims database [Symphony Health Integrated Dataverse ${ }^{\circledR}$ (IDV)]. Patients were identified using ICD codes for MS and considered to have relapsing/remitting type according to established claims-based methodology. Clinical characteristics and HCRU were

J. B. Rice $(\bowtie) \cdot$ A. White $\cdot$ M. Simes $\cdot$ E. Billmyer

N. Downes

Analysis Group Inc., Boston, MA, USA

e-mail: Brad.Rice@AnalysisGroup.com

M. P. Panaccio · J. Niewoehner · G. J. Wan

Mallinckrodt Pharmaceuticals, Bedminster, NJ, USA analyzed during the year preceding ("baseline") and the year following ("follow-up") each patient's index date, defined as the date of a patient's first approved RCI claim (for patients with $\geq 1$ approved claim) or first denied RCI claim (for patients with only denied claims). Baseline characteristics were reported with unadjusted differences and $p$ values indicating the significance of characteristics between the two cohorts. For outcomes, match-adjusted results were reported using propensity matching to account for underlying differences between cohorts.

Results: The study sample included 1902 MS relapse patients with at least one claim for RCI. At baseline, approved patients were slightly older compared to denied patients (mean age 48.0 vs. 47.2), had higher rates of hemiplegia/paraplegia (6.7\% vs. $3.3 \%)$, greater mobility impairment (17\% vs. $11.5 \%)$, more exacerbation episodes (66.2\% vs. $59.9 \%)$, and a higher number of physical therapy/rehab claims (23.5 vs. 14.0), respectively. Outcomes among the matched sample show an increased use of corticosteroids for patients denied access to RCI compared to approved patients $(51.1 \%$ vs. $42.4 \%$ ), more exacerbation episodes (36.6\% vs. $28.2 \%)$, and an increased number of physical therapy/rehab claims $(11.5 \%$ vs. $9.9 \%)$, respectively.

Conclusion: The results of this study may aid providers and payers in evaluating scenarios where RCI may be beneficial and improve 
quality of care for patients experiencing MS relapse.

$\begin{array}{lcr}\text { Keywords: Multiple } & \begin{array}{c}\text { sclerosis } \\ \text { multiple }\end{array} & \begin{array}{r}\text { relapse; } \\ \text { sclerosis; }\end{array} \\ \text { Relapsing-remitting } & \begin{array}{l}\text { Repository corticotropin injection } \\ \text { Reping }\end{array}\end{array}$

\section{Key Summary Points}

Why carry out the study?

Repository corticotropin injection (RCI; Acthar ${ }^{\circledR} \mathrm{Gel}$ ) is indicated for the treatment of acute exacerbations of multiple sclerosis (MS) in adults.

Despite the well-documented clinical and economic benefits of RCI treatment for MS relapse, many patients are denied access to RCI by third-party payers.

By implementing a retrospective cohort design of de-identified claims data, this study aims to understand the demographic and clinical characteristics of 1902 MS relapse patients who were either approved or denied access to RCI treatment by their insurers.

\section{What was learned from the study?}

Compared to the approved cohort, patients denied access to RCI had measurably worse outcomes and greater healthcare resource use (HCRU) along a number of dimensions during the followup period, including: increased use of corticosteroids, higher rates of MS exacerbation episodes, and more physical therapy/rehab claims.

The results of this real-world study may aid providers and payers in evaluating scenarios where RCI may be beneficial and improve quality of care for patients experiencing MS relapse.
Future research may consider expanding this analysis to larger sample sizes to assess whether the trends of clinical worsening and increased HCRU hold among MS relapse patients denied access to RCI treatment relative to those approved.

\section{DIGITAL FEATURES}

This article is published with digital features to facilitate understanding of the article. You can access the digital features on the article's associated Figshare page. To view digital features for this article go to https://doi.org/10.6084/m9. figshare.13017215.

\section{INTRODUCTION}

Multiple sclerosis (MS) is a chronic and debilitating disease of the central nervous system (CNS), currently estimated to affect over 900,000 adults in the United States [1]. The recurrent inflammation of the CNS that is characteristic of MS results in damage to nerve cells, causing symptoms that may include numbness or paralysis of the limbs, visual disturbances, bladder or bowel dysfunction, sexual dysfunction, or the loss of control of bodily movements [2].

Four distinct types of MS have been identified, each with their own particular disease course and prognosis: relapsing-remitting, secondary progressive, primary progressive, and progressive relapsing MS. Relapsing-remitting MS (RRMS) is the most common (72.2\%) diagnosis, characterized by acute exacerbations of neurologic dysfunction that evolve over a period of days to weeks. Most patients with relapsing-remitting type MS experience a recovery from these exacerbations (though not always complete) after several weeks or months $[2,3]$. Approximately $85 \%$ of MS patients are initially diagnosed with RRMS [4]. Among RRMS patients, a recent study estimates the incidence of high disease activity at $8.5 \%$ [5]. Because 
patients are neurologically and symptomatically stable between periods of exacerbation, there is enormous value in providing patients with treatments that mitigate the symptoms of acute relapses and accelerate recovery.

Current first-line treatments for MS relapse exacerbations include corticosteroids (CS) that may be prescribed to patients to be taken orally or administered intravenously in a clinical setting. Intravenous administration of CS requires multiple infusions and, in addition to interfering with a patient's daily life, is more costly than oral CS [6-8]. In both cases, high doses of CS are accompanied by a number of adverse effects that may not be tolerated well among MS patients [9-11]. Alternative, second-line, treatments for MS relapse include plasmapheresis (PMP), intravenous immunoglobulin (IVIG), and repository corticotropin injection (RCI). The Multiple Sclerosis Association of America points out that, for more than 30 years, RCI has been used as an alternative to CS to treat relapses of MS [12]. Currently, Acthar ${ }^{\circledR}$ Gel is the only branded RCI available in the U.S. that is approved for treatment of acute exacerbations of MS relapse in adults and can be self-administered $[6,13,14]$.

Numerous studies have demonstrated that RCI treatment increases recovery rates and improves disability scores in patients experiencing acute MS relapse exacerbations [15-20]. Other studies assessing the economic benefits of RCI have found that RCI treatment for MS relapse is associated with fewer hospitalizations and outpatient service visits as well as lower costs in inpatient and outpatient services when compared to alternative second-line treatments $[21,22]$.

Despite the clinical and economic evidence supporting the efficacy, safety, and benefits of RCI treatment for acute MS relapse [23], many patients suffering from MS relapse are denied access to RCI treatment by third-party payers in the U.S. This study aims to understand the demographic and clinical characteristics of MS relapse patients approved for RCI treatment compared to MS relapse patients denied access to RCI treatment by third-party payers, as well as to compare measurable clinical outcomes and healthcare resource utilization (HCRU) for MS relapse patients whose prescription claims for RCI are either approved or denied.

\section{METHODS}

\section{Overview}

To understand the demographic and clinical characteristics of MS relapse patients approved for RCI treatment compared to MS relapse patients denied access to RCI, this study implemented a retrospective cohort analysis of a de-identified open-source claims database (Symphony Health Integrated Dataverse ${ }^{\circledR}$ [IDV]). The study also compares clinical outcomes and HCRU for MS relapse patients ultimately receiving access to RCI treatment versus those patients who never received access to RCI in the time period covered by the data. Demographic and clinical characteristics and HCRU were assessed during a baseline period, defined as the 12 months preceding a patient's index date; the index date for each patient was defined as the date of the first approved RCI claim (for approved patients) or the date of the first denied claim (for denied patients).Clinical outcomes and HCRU for approved and denied patients were compared during a follow-up period, defined as the 12 months following the first approved or denied claim for patients in their respective cohorts. The difference in clinical outcomes and HCRU between MS relapse patients approved for RCI treatment versus those denied were assessed during the follow-up period using a matched case-control study design to account for baseline differences in patient demographic and clinical characteristics as well as prior HCRU and costs.

\section{Data Source}

This study used a de-identified open-source claims database (Symphony Health IDV) that links data from pharmacy point-of-service systems, payer adjudication services (clearinghouses), and direct prescription, medical, and hospital feeds. These data contain approximately 168 million longitudinally tracked 
patients with prescription and medical claims in any recent year of the database. Patients in the database are representative of the U.S. population age and gender mix with claims from diverse payers including basic Medicaid, Managed Medicaid, Medicare, assistance programs, commercial insurers, and cash payers. The database captures prescription claims from two types of data streams: clearinghouse claims that have been processed through a payer's adjudication system and direct-feed claims from pharmacy point-of-service systems. For claims processed through payers' adjudication systems, the data contain the full cycle of a patient's claim adjudication status, making it possible to analyze a patient's history of denied and approved claims. For claims originating in pharmacy point-of-service systems, only the final approved status of the claim is available. All prescription claims in the data contain detailed information regarding dispensation (final claim approval status, fill dates, national drug codes, dosing information, and payment amounts), making it possible to track patients who received access to a particular drug versus those who were denied access by U.S. payers.

\section{Sample Selection}

In order to be eligible for the study, patients were required to have submitted at least one prescription claim for RCI, either approved or denied, during the study period of January 1 , 2015, through December 31, 2018. Prescription claims for RCI were identified in the data using Generic Product Identifier codes (GPI), National Drug Codes (NDC), and codes from the Healthcare Common Procedural Coding System (HCPCS). In addition to having at least one prescription claim for RCI in the data, patients were required to have at least one medical claim associated with MS relapse. Because the data only report a diagnosis of MS (ICD-9-CM code 340 and ICD-10-CM code G35) and do not specify the relapsing/remitting subtype, the study implemented a claims-based algorithm used in previously published, peer-reviewed literature to identify patients experiencing RRMS $[20,22,24,25]$. To be included in the study, the algorithm required patients to have either one or more inpatient claims with a diagnosis code for MS or at least one other type of clinical encounter (e.g., outpatient, physician office visit, other medical visit claim) with an MS diagnosis code in combination with the use of any qualifying CS prescription within 7 days of that visit, or with the use of either RCI, PMP, or IVIG treatment within 30 days of that visit.

Based on their prescription history in the data, patients meeting the above criteria were divided into two mutually exclusive cohorts: patients approved for RCI treatment (i.e., patients having at least one approved prescription claim in the data) and patients denied access to RCI (i.e., patients having no approved claims in the data). Patients in both cohorts were required to be aged 18 years or older on their index date and to have at least 12 months of eligibility during the baseline period and at least 12 months of eligibility during the followup period. Because the data aggregate a patient's medical and prescription claim activity over time from a diverse set of sources and do not definitively report the time frame of a patient's insurance eligibility, the study utilized the date stamps of a patient's claims activity to approximate the length of the patient's insurance eligibility. To ensure that all relevant medical and prescription claims were captured during a patient's baseline and follow-up periods, patients were required to have at least one active claim in the data during the first 3 months of their baseline period (i.e., months 9-12 prior to their index date) and during the last 3 months of their follow-up period (i.e., months 9-12 after their index date).

\section{Statistical Analyses}

To compare outcomes with minimal bias between patients who were approved for RCI treatment and those who were denied, the study reports outcomes for patients taking into account the underlying differences between the two cohorts. Specifically, approved patients were matched one-to-one to denied patients based on a propensity score derived from the characteristics assessed during the baseline 
period using a "greedy" matching methodology [26]. Propensity scores were calculated for patients using a multivariable logistic regression that took into account all of the covariates measured at baseline. Approved and denied patients were matched one-to-one according to the nearest propensity score $( \pm 1 / 4$ of a standard deviation).

For categorical variables, statistical significance was assessed using chi-square tests for comparisons between pre-match (unadjusted) outcomes, and McNemar tests for the matched (adjusted) cohorts. For continuous variables, statistical significance was assessed using Wilcoxon rank-sum tests (pre-match, unadjusted) and Wilcoxon signed-rank tests (post-match, adjusted). Statistical analyses were performed separately for each cohort using SAS Enterprise Guide version 7.15 (SAS Institute Inc., Cary, NC).

\section{Study Measures}

Key demographic, HCRU, and clinical characteristics relevant to MS relapse diagnosis and disease severity were evaluated for both the approved and denied cohorts. Patient demographics included a patient's age at the time of their index date, gender, U.S. census region, the year in which their index date occurred, and insurance plan type (e.g., Medicare, Medicaid, commercial, and other/unspecified). Clinical characteristics evaluated in the baseline period included the time elapsed since a patient's initial MS relapse diagnosis in the data in addition to the number of claims with a diagnosis for MS relapse. During the baseline period, the study also reported patients' Charlson Comorbidity Index (a composite measure of the patient's health status) [27] as well as the incidence of other comorbidities commonly observed in patients with MS relapse including mood disorder diagnoses, abnormality of gait, fibromyalgia and myositis, and optic neuritis.

For both baseline and follow-up periods, the study assessed the severity of MS relapse in each cohort by tracking the number of MS exacerbations using a claims-based algorithm to identify relapse episodes [20, 22, 24].
Additionally, with regard to measuring severity before and after the index date, the study analyzed indicators of limited mobility, such as the use of certain medical devices (e.g., cane/crutch, walker, wheelchair, and/or specialty bed), use of dalfampridine (Ampyra; indicated for walking disability), and the average number of Expanded Disability Status Scale (EDSS)-derived disability claims per patient $[28,29]$.

In the follow-up period only, the study assessed a subset of American Academy of Neurology-defined neurologic impairment indicators where patients received treatment to address comorbidities in any of the following categories: pain, fatigue, depression, psychosis, cognitive impairment [30]. Additionally, the utilization of MRI procedures was analyzed as an outcome of interest for both cohorts. Also tracked during the follow-up period were the number of patients with MS relapse exacerbation episodes.

Total all-cause HCRU and medical costs were examined for approved and denied patients in both periods. To compare the utilization of prescription medication between cohorts, the average number of prescriptions per patient was assessed. The study also analyzed the utilization of selected treatments relevant to MS relapse including CS use (e.g., the average number of CS prescriptions per patient along with the annualized average daily and maximum dosing), the use of disease-modifying anti-rheumatic drugs (DMARDs), and MS-related treatments of PMP, IVIG, and other disease-modifying therapies (DMTs). HCRU and medical costs were categorized by place of service to identify sources of differential utilization. Place of service categories included the following: inpatient, outpatient/physician office, and other. In addition, the utilization of physical therapy/rehabilitation services by patients and the average number of those claims per patient were assessed.

\section{Description of Approval Process}

For the subset of patients for which the "full claim cycle" is available (i.e., the data containing all approvals and denials), the study examined the approval process using aggregate 
summary statistics that took into account the number of patients with no approved claims and the average number of denied claims for those patients. For the approved cohort, the study analyzed the distribution of denied claims prior to approval as well as the average number of approved claims per patient.

\section{Compliance with Ethics Guidelines}

Because of the nature of the retrospective study design using previously collected, de-identified data, institutional review board (IRB) approval was not necessary for this study.

\section{RESULTS}

\section{Sample Selection}

In the Symphony Health IDV database, there were 20,767 patients with at least one prescription claim for RCI during the study period; 1902 of those patients were flagged by the sample selection algorithm identifying MS relapse and met the inclusion criteria of being 18 years of age or older on their index date, with at least 12 months of eligibility during both their baseline and follow-up periods. Out of the 1902 MS relapse patients eligible for the sample, 1633 patients had at least one approved claim for RCI, while 269 patients had no approved RCI claims. Among all approved and denied patients in the sample, the full claim cycle (i.e., the history of approvals and/or denials of their RCI claims) was available for 919 patients; conversely, 983 patients had only direct feed claims. Because direct feed claims in the data originate from pharmacy point-of-sale feeds, they are necessarily approved claims (i.e., they are entered at the time of dispensing and payment). Thus, the 983 patients with direct feed only claims are included in the 1633 patients that make up the approved cohort (Fig. 1).

\section{Approval Process}

Of the 919 patients in the sample for whom the full claims cycle (i.e., full history of approvals and denials) was available, 70.73\% $(N=650)$ had at least one approved claim for RCI and $29.27 \%(N=269)$ had no approved claims for $\mathrm{RCI}$ in the data. Analysis of the approval process showed that $59.54 \%$ of patients with an approved prescription for RCI had no denied claims in the data, meaning that the remaining $40.46 \%$ of patients in the approved cohort had at least one denied claim prior to being approved. The mean number of approved claims for all patients in the approved cohort was 2.34. For the 269 patients in the denied cohort, for whom the full claims cycle was available, the mean number of denied claims was 2.92, indicating that these patients had their claims reviewed, on average, roughly three times before they were finally denied access to RCI treatment by their third-party payer (Table 1).

\section{Baseline Characteristics}

During the 12-month baseline period, patients who had been approved for RCI treatment were observably different from the population denied access to RCI along a number of different dimensions examined (Table 2). Approved patients were slightly older (mean age 48.0) compared to denied patients (mean age: 47.2). Approved patients also had higher rates of hemiplegia/paraplegia $(6.7 \%$ vs. $3.3 \%)$ and greater indicators of mobility impairment $(17.0 \%$ vs. $11.5 \%)$. Approved patients experienced more exacerbation episodes than denied patients $(66.2 \%$ vs. 59.9\%), and incurred a higher number of physician treatment rehab claims (mean 23.5 vs. 14.0) during baseline.

\section{Matching Results}

Propensity score matching based on a logistic regression that used all of the variables assessed during the baseline period produced an overall sample of 262 approved and 262 denied patients for whom adjusted outcomes could be compared. The size of the denied cohort prior to matching was 269 patients; $97 \%$ of all patients in the denied cohort, therefore, were matched to a patient from the approved cohort, 


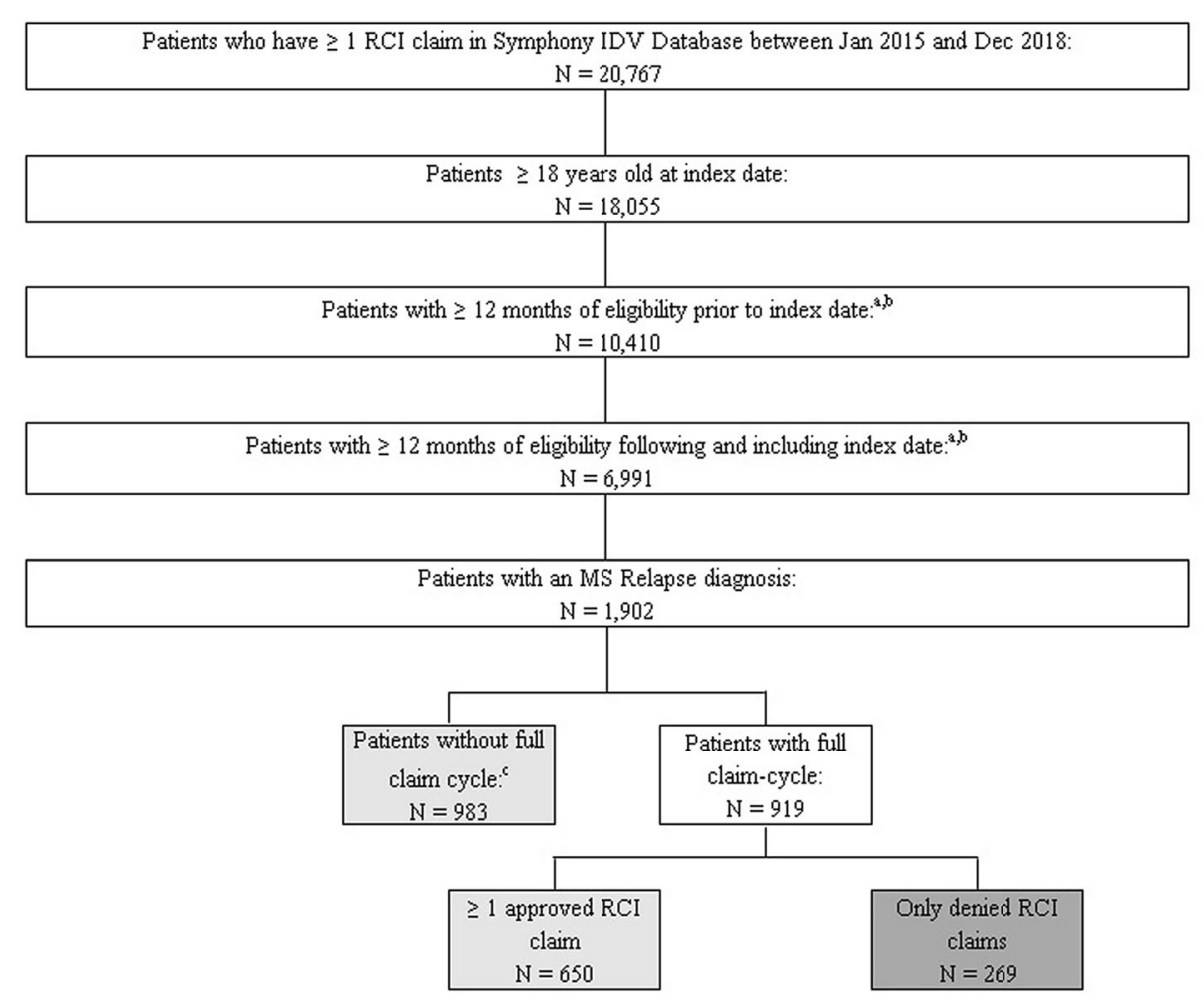

\footnotetext{
${ }^{a}$ For patients that have at least 1 approved RCI claim, the index date is the date of the first approved claim. For patients that only have denied RCI claims, the index date is the date of the first denied claim.

${ }^{b}$ A patient is assumed to have eligibility in the baseline period if they have a medical or prescription claim $9-12$ months before the index date. $A$ patient is assumed to have eligibility in the follow-up period if they have a medical or prescription claim 9-12 months after the index date. Symphony IDV does not contain eligibility information.

"Patients without full-claim cycle are patients that have only direct feed claims, all of which are approved. Direct feed claims originate from point of sale data streams and therefore do not include denied claims.

RCI repository corticotropin injection
}

Fig. 1 Sample selection of patients with MS relapse and assignment to cohorts based on approval or denial of RCI claims

minimizing concerns for potential bias in the comparison of outcomes between the two cohorts. While many of the outcomes observed among the matched sample did not reach conventional levels of statistical significance, we nonetheless report outcomes in categories that point to clinically relevant distinctions between patients who were denied access to RCI treatment relative to those who were approved. To identify potentially clinically relevant distinctions between the two cohorts, the study reports outcomes among the matched sample that cross a threshold of $>10 \%$ relative difference between approved and denied patients, unless otherwise noted.

\section{MS Exacerbations During the Follow-Up Period}

Although more patients in the approved cohort had exacerbation episodes than patients denied access to RCI during the baseline period $(66.2 \%$ of approved patients vs. $59.9 \%$ of denied patients), this trend is reversed in the comparison of matched outcomes. During the followup period, $36.6 \%$ of patients who were denied access to RCI experienced at least one exacerbation episode; only $28.2 \%$ of patients from the approved cohort, by contrast, experienced at least one exacerbation episode (Table 3). 
Table 1 Approval process for MS relapse patients with full claim cycle

\begin{tabular}{ll}
\hline Total cohort: no. of patients with at least 1 RCI claim & $\begin{array}{l}\text { Number (\%) or mean } \mathbf{\pm} \text { SD } \\
(\boldsymbol{n}=\mathbf{1 9 0 2})\end{array}$ \\
\hline Number with incomplete claims cycle & $983(51.7 \%)$ \\
Number with full claims cycle & $919(48.3 \%)$ \\
Denied patients & $269(29.27 \%)$ \\
$\quad$ Mean number of denied claims & $2.92 \pm 3.7$ \\
Approved patients & $650(70.73 \%)$ \\
Mean number of approved claims per patient & $2.34 \pm 3.01$ \\
Mean number of denied claims per patient prior to approval & $0.72 \pm 1.24$ \\
0 denied claims & $59.54 \%$ \\
1 denied claim & $25.54 \%$ \\
2 denied claims & $7.08 \%$ \\
3 denied claims & $3.69 \%$ \\
4 denied claims & $2 \%$ \\
$5+$ denied claims & $2.15 \%$ \\
\hline
\end{tabular}

$R C I$ repository corticotropin injection

\section{HCRU and Medical Costs During the Follow-Up Period}

Match-adjusted outcomes show that MS relapse patients denied access to RCI had, on average, greater HCRU than patients who had their RCI claims approved. The denied cohort had substantially more patients requiring an inpatient admission compared to the approved cohort during the 12-month follow-up period (61 vs. 40 ). Additionally, greater use of physical therapy/rehab services was observed among the denied cohort, with increases in both the number of patients with physical therapy/rehab claims (30 vs. 26) and the average number of physical therapy/rehab claims per patient (23.8 vs.14.2). The denied cohort also incurred noticeably higher medical costs $(\$ 29,467$ vs. $\$ 23,378$ ) that were largely driven by greater costs in outpatient/physician office visits $(\$ 24,140$ vs. $\$ 20,836)$ and other visits ( $\$ 4574$ vs. $\$ 1849$ ) compared to the approved cohort (Table 3).

\section{Prescription Drug Use and MS-Related Treatments During the Follow-Up Period}

The use of CS was greater among patients denied RCI use compared to the approved cohort in terms of both the number of patients with prescriptions for CS (134 vs. 111) and the annualized average daily dose of CS (1.2 mg vs. $0.8 \mathrm{mg}$ ). The denied cohort also showed a slight increase $(<10 \%$ relative difference) in the number of patients being treated with other disease-modifying therapies (121 vs. 117) as well as an increase in the number of patients being treated for cognitive impairment, and slight increases $(<10 \%$ relative difference) in the number of patients being treated for other neurologic impairments such as pain and fatigue.

\section{DISCUSSION}

Based on the comparison of baseline characteristics for 1902 MS relapse patients before matching, the cohort ultimately approved for 
Table 2 Patient demographics and clinical characteristics during the baseline period

Baseline characteristics
Multiple sclerosis patients

$N=1902$

$\begin{array}{ll}\underset{\substack{\text { Approved patients } \\(n=1633)}}{(n=269)} & \begin{array}{l}\text { Denied patients } \\ \left(n=\text { value }^{\mathrm{a}}\right.\end{array}\end{array}$

Demographics

Age, mean \pm SD [median]

Gender, female

$48.0 \pm 11.6[48]$

$47.2 \pm 11.1[47]$

0.42

$1362(83.4 \%)$

$213(79.2 \%)$

0.09

Year of index date

2015

2016

2017

Region

Midwest

$356(21.8 \%)$

$345(21.1 \%)$

$766(46.9 \%)$

$163(10.0 \%)$

$3(0.2 \%)$

$37(2.3 \%)$

$108(6.6 \%)$

$129(7.9 \%)$

$399(24.4 \%)$

$173(10.6 \%)$

$802(49.1 \%)$

$0.5 \pm 1.1[0]$

$0.4 \pm 1.0[0]$

0.11

Charlson Comorbidity Index, mean \pm SD [median]

Condition-specific comorbidities

Abnormality of gait

Fibromyalgia/myalgia and myositis

Hemiplegia or paraplegia

Mood disorder diagnoses

Optic neuritis

$312(19.1 \%)$

$136(8.3 \%)$

$110(6.7 \%)$

$454(27.8 \%)$

$112(6.9 \%)$

$36(2.2 \%)$

$5(1.9 \%)$
$<0.0001$

$<0.01$

$<0.0001$

0.14

0.87

0.89

0.04

1.00

0.10

$<0.0001$

0.24

0.12

0.04

$<0.01$
Other autoimmune diseases

Lupus

$41(15.2 \%)$

0.13

0.26

0.03

$9(3.3 \%)$

0.21

65 (24.2\%)

0.90

$19(7.1 \%)$

(n)
- 
Table 2 continued

\section{Baseline characteristics}

Nephrotic syndrome

Rheumatoid arthritis

Sarcoidosis

Proxies for disease severity, mean \pm SD [median]

Days between diagnosis and index date

Patients with MS exacerbations

Number of MS relapse diagnoses/exacerbations

Number of MS relapse diagnoses in inpatient setting

Mobility indicators

Overall

Cane/crutch

Dalfampridine (Ampyra)

Specialty bed

Walker

Wheelchair

EDSS-derived disability claims, mean $\pm \mathrm{SD}$ [median]

Condition-specific healthcare resource utilization

Rehabilitation and physical therapy services

Patients with $\geq 1 \mathrm{rehab} /$ physical therapy claim

Number of rehab/physical therapy claims

Corticosteroid (CS)

Patients with $\geq 1$ CS

Number of CS claims, mean \pm SD [median]

Annualized average daily dose (mg), mean \pm SD [median]

Maximum CS dose (mg), mean \pm SD [median]

Number of patients w/high dose $(15 \mathrm{mg} /$ day) CS use

DMARD use

Anti-TNF drugs

Mean \pm SD no. of Rxs

Other biologics

Multiple sclerosis patients

$N=1902$

Approved patients

$(n=1633)$

Denied patients

$p$ value $^{\mathbf{a}}$

$(n=269)$

$51(3.1 \%)$

$4(1.5 \%)$

0.14

$50(3.1 \%)$

$11(4.1 \%)$

0.38

$19(1.2 \%)$

$3(1.1 \%)$

1.00

$25.0 \pm 323.6$ [19]

$80.3 \pm 330.2[18]$

0.83

$1081(66.2 \%)$

$161(59.9 \%)$

0.04

$1.2 \pm 2.2[1]$

$0.9 \pm 1.2[1]$

0.05

$0.6 \pm 2.0[0]$

$0.4 \pm 1.1[0]$

0.67

277 (17.0\%)

$31(11.5 \%)$

0.02

$16(1.0 \%)$

$2(0.7 \%)$

1.00

$203(12.4 \%)$

$22(8.2 \%)$

0.05

$8(0.5 \%)$

$1(0.4 \%)$

1.00

$45(2.8 \%)$

$5(1.9 \%)$

0.39

$23(1.4 \%)$

$2(0.7 \%)$

0.56

$4.4 \pm 6.4[1]$

$4.2 \pm 6.9[1]$

0.54

264 (16.2\%)

$23.5 \pm 33.4[11]$

893 (54.7\%)

$1.6 \pm 2.6[1]$

$1.3 \pm 3.6[0]$

$7.5 \pm 11.2[0]$

$149(9.1 \%)$

$4(0.2 \%)$

$0.0 \pm 0.4[0]$

$10(0.6 \%)$
$0(0.0 \%)$

1.00

$33(12.3 \%)$

0.10

$14.0 \pm 17.6[8]$

0.37

$1.6 \pm 2.3[1]$

0.46

$1.3 \pm 2.9[0]$

0.36

$7.8 \pm 11.1[0]$

0.44

0.93

$25(9.3 \%)$

$0.0 \pm 0.0[0]$

0.42

$1(0.4 \%)$ 
Table 2 continued

\section{Baseline characteristics}

\begin{tabular}{llc}
\hline \multicolumn{3}{l}{ Multiple sclerosis patients } \\
\hline $\boldsymbol{N = 1 9 0 2}$ & & \\
\hline $\begin{array}{l}\text { Approved patients } \\
(\boldsymbol{n}=\mathbf{1 6 3 3})\end{array}$ & $\begin{array}{l}\text { Denied patients } \\
(\boldsymbol{n}=\mathbf{2 6 9})\end{array}$ & $\boldsymbol{p}$ value $^{\mathbf{a}}$ \\
$4.9 \pm 3.8[4]$ & $2.0 \pm .[2]$ & 0.44 \\
$23(1.4 \%)$ & $2(0.7 \%)$ & 0.56 \\
$3.9 \pm 3.3[3]$ & $8.5 \pm 2.1[9]$ & 0.10 \\
$68(4.2 \%)$ & $9(3.3 \%)$ & 0.53 \\
$4.0 \pm 3.4[3]$ & $4.8 \pm 3.5[4]$ & 0.44 \\
$9(0.6 \%)$ & & \\
$10(0.6 \%)$ & $1(0.4 \%)$ & 0.62 \\
$1006(61.6 \%)$ & $130(48.3 \%)$ & $<0.0001$
\end{tabular}

All-cause healthcare resource utilization ${ }^{c}$

Medical

Inpatient

Patients with $\geq 1$ visit

$380(23.3 \%)$

$60(22.3 \%)$

0.73

Visits per patient, mean \pm SD [median]

$2.0 \pm 1.8[1]$

$1.9 \pm 1.6[1]$

0.92

Days per visit, mean \pm SD [median]

$5.9 \pm 7.8[3]$

$5.1 \pm 5.8[3]$

0.52

Outpatient

Patients with $\geq 1$ visit

$$
1526(93.4 \%)
$$

$252(93.7 \%)$

Visits per patient, mean \pm SD [median]

$12.2 \pm 12.2[8]$

$10.0 \pm 9.5[7]$

Other place of setting

$$
\text { Patients with } \geq 1 \text { visit }
$$

$879(53.8 \%)$

$131(48.7 \%)$

0.12

Visits per patient, mean \pm SD [median]

$6.8 \pm 17.5[3]$

$9.4 \pm 30.8[3]$

0.58

Prescription, mean \pm SD [median]

Total prescriptions filled per patient

$50.8 \pm 44.8[39]$

$42.3 \pm 39.5[29]$

$<0.01$

Unique prescriptions filled per patient

$15.8 \pm 12.0[13]<0.01$

DMARD disease-modifying antirheumatic drug, TNF tumor necrosis factor, EDSS Expanded Disability Status Scale

${ }^{a}$ Statistical comparisons were conducted using the Wilcoxon rank-sum test for continuous variables and chi-square test for dichotomous variables

b Other/unspecified insurance plan type includes processors, third-party-administered insurance, and unspecified plan types

c The Symphony data list all visits that are not inpatient or outpatient, or surgery as "other" 
Table 3 Clinical outcomes and healthcare resource utilization during the follow-up period

Matched MS patients ${ }^{a}$

\begin{tabular}{lll}
\hline $\begin{array}{c}\text { Approved patients } \\
(n=262)\end{array}$ & $\begin{array}{l}\text { Denied patients } \\
(n=262)\end{array}$ & $p$ value $^{\mathrm{b}}$
\end{tabular}

MS-specific characteristics and HCRU

MS exacerbation episode

$\geq 1$ exacerbation episode

Patients with 1 exacerbation episode

Patients with 2 exacerbation episodes

Patients with $\geq 3$ exacerbation episodes

Neurologic impairment indicators

Pain

Fatigue

Depression

Psychosis

Cognitive impairment

MS-related treatments

Plasmapheresis

Intravenous immunoglobulin

Other disease-modifying therapy

Rehabilitation and physical therapy services

Patients with $\geq 1 \mathrm{rehab} /$ physical therapy claim

Number of rehab/physical therapy claims

Mobility indicators

Overall

Cane/crutch

Dalfampridine (Ampyra)

Specialty bed

Walker

Wheelchair

EDSS-derived disability claims

Procedures

$$
\text { MRI }
$$

$91(34.7 \%)$

$50(19.1 \%)$

$10(3.8 \%)$

$14(5.3 \%)$

$78(29.8 \%)$

$3(1.1 \%)$

$0(0.0 \%)$

$3(1.1 \%)$

26 (9.9\%)

$0(0.0 \%)$

4 (1.5\%)

7 (2.7\%)

$1(0.4 \%)$
96 (36.6\%)

0.04

75 (28.6\%)

$<0.01$

$8(3.1 \%)$

0.64

$13(5.0 \%)$

0.85

$79(30.2 \%)$

0.93

78 (29.8\%)

134 (51.1\%)

$101(38.5 \%)$

$83(31.7 \%)$

0.62

$129(49.2 \%)$

0.66

$91(34.7 \%)$

0.37

7 (2.7\%)

0.21

$2(0.8 \%)$

1.00

$1(0.4 \%)$

0.32

117 (44.7\%)

$121(46.2 \%)$

0.71

$30(11.5 \%)$

0.56

$14.2 \pm 15.2[5]$

$23.8 \pm 44.3[7]$

0.88

$39(14.9 \%)$

$39(14.9 \%)$

1.00

$3(1.1 \%)$

1.00

$30(11.5 \%)$

$25(9.5 \%)$

0.46

$3(1.1 \%)$

0.71

$6(2.3 \%)$

0.78

7 (2.7\%)

0.03

$4.6 \pm 6.9[1]$

$4.9 \pm 6.7[1]$

0.48

All-cause healthcare resource use

$\geq 1$ visit 
Table 3 continued

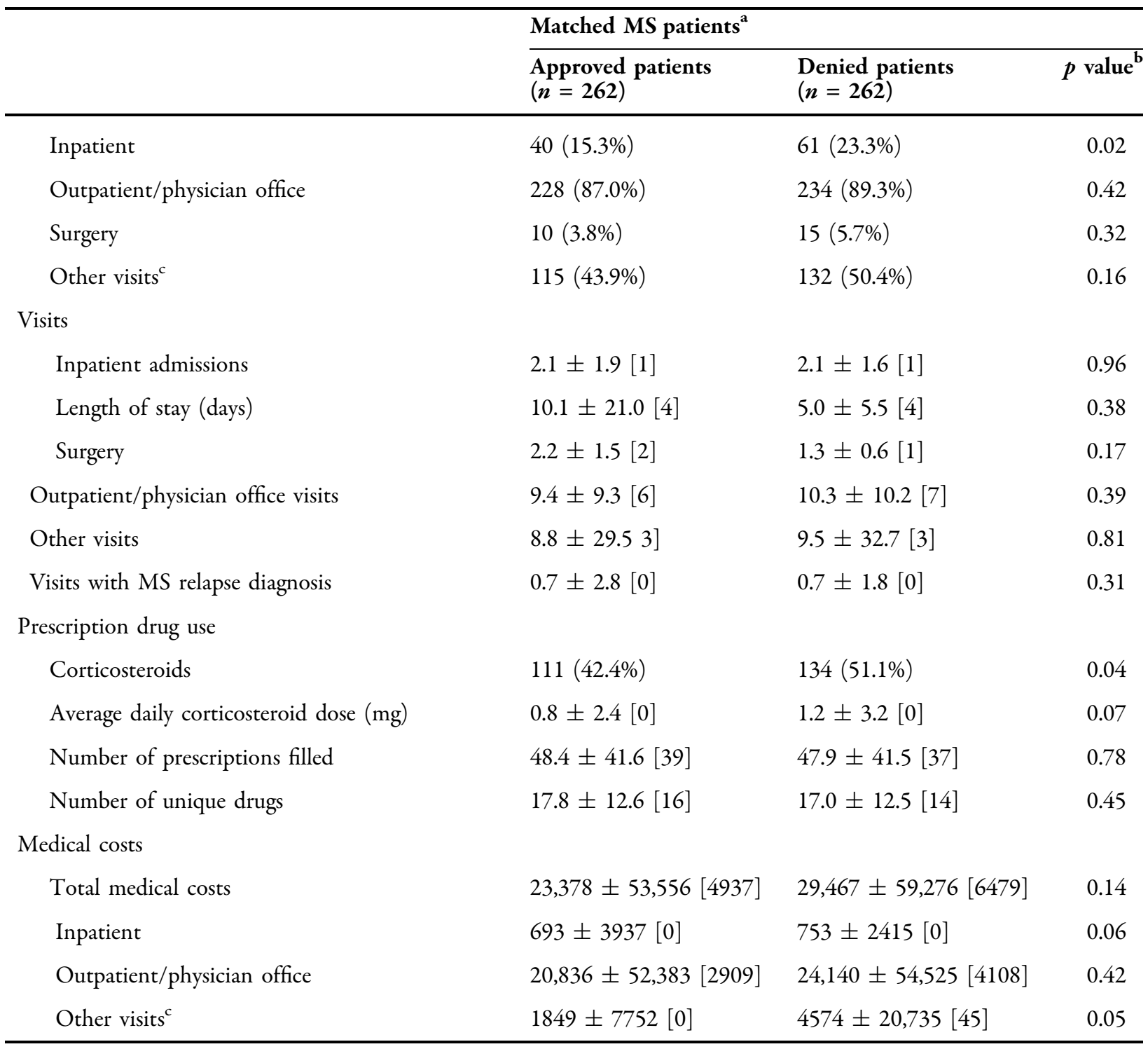

$H C R U$ healthcare resource utilization, EDSS Expanded Disability Status Scale

${ }^{a}$ Denied patients are propensity score-matched ( $\pm 1 / 4$ SD) 1:1 to approved patients. The matching criteria include all baseline characteristics reported in the baseline tables

b Statistical comparisons were conducted using the Wilcoxon signed-rank test for continuous variables and the McNemar test for dichotomous variables

c The Symphony data list all visits that are not inpatient, outpatient, or surgery as "other"

RCI treatment was, on average, older than patients in the denied cohort and was observably worse along several clinical dimensions (e.g., rates of hemiplegia/paraplegia, mobility indicators, and incidence of exacerbations) relating to the severity of disease. At baseline, the approved cohort also exhibited greater use of other DMTs and had higher HCRU. Taken 
together, these observations imply that disease severity and rates of HCRU may play a role in the decision process of third-party payers when evaluating patients' prescription claims for RCI.

Matching approved and denied patients according to the characteristics measured in the baseline period allowed the study to compare, with minimal bias, outcomes for patients who received access to RCI to those who did not. This comparison showed that denied patients had measurably worse clinical outcomes and greater resource use during the 12-month follow-up period. Denied patients were also more likely to require inpatient admissions, physical therapy/rehab, and the use of a wheelchair than those in the approved cohort. Notably, patients in the denied cohort experienced a greater number of exacerbation episodes despite having similar rates of other DMT use as approved patients. The worsening clinical outcomes observed in the denied cohort during the follow-up period, such as the increased rates of exacerbation episodes relative to the approved cohort, a greater use of physical therapy/rehab services, and higher rates of treatment for neurologic impairment, is likely a key driver in the higher healthcare resource use for denied patients. These results are consistent with previous studies that demonstrate the clinical and economic benefits of RCI in treating MS relapse $[20,22]$.

Because the Symphony IDV used in this study indicates the payer type for each prescription claim, it was possible to compare outcomes for a subset of the approved and denied cohorts with claims submitted to commercial payers $(N=167)$ and Medicare $(N=111)$ (Table 4$)$. While the trends of generally worsening clinical outcomes for denied patients hold after stratifying by payer type, it was observed that commercially insured patients who were denied access to RCI had higher EDSS-derived disability claims than their approved counterparts, and Medicare patients in the denied cohort were more likely to require treatment for neurologic impairment (e.g., pain, fatigue, depression, and cognitive impairment) than Medicare patients who were treated with RCI. The American Academy of Neurology indicates that both EDSS-derived disability indicators and the neurologic indicators that were analyzed in this study are key metrics, among others, for assessing and improving the quality of care for patients with MS [30]. Therefore, the present study's observations of lower rates of EDSS-derived disability claims and neurologic impairment among patients who were approved for RCI treatment (among specific payer types and in the overall matched sample) may serve as important considerations for clinicians and payers in improving the quality of care for patients with MS relapse [31, 32].

This study had limitations inherent in the data used for the analysis. Because the Symphony IDV is an open-source data base linking patient claims from diverse data feeds, the database does not contain complete eligibility records for patients, and thus it is possible that not all claims for a given patient may be captured in the data. However, out of all patients with a prescription claim in the data, $72 \%$ had at least one medical claim which allowed the study to approximate eligibility relative to the baseline and follow-up periods. Additionally, the data do not contain lab values for clinical tests. Clinical measures of severity, therefore, were assessed based on treatment and resource use relying on IDC diagnosis codes and CPT codes associated with a particular claim. Finally, while the data are uniquely rich in a number of dimensions, the sample size was limited after implementing the full set of analytic criteria and matching methodology. As a result, most outcomes did not reach conventional levels of statistical significance. However, we interpret the observed differences between approved and denied cohorts to be indicative of clinically relevant distinctions between those who receive RCI treatment for MS relapse and those who do not. Future researchers may consider expanding this analysis into larger studies, where possible, to assess whether these observed trends remain consistent in larger sample sizes.

\section{CONCLUSIONS}

This study is the first to use rigorous methodologies to estimate the impact of RCI treatment 
Table 4 Clinical outcomes and healthcare resource utilization during the follow-up period (Medicare vs. commercial plan type)

\begin{tabular}{|c|c|c|c|c|c|c|}
\hline & \multicolumn{3}{|c|}{ Matched MS patients ${ }^{\mathrm{a}}-$ commercial } & \multicolumn{3}{|c|}{ Matched MS patients ${ }^{\mathrm{a}}-$ Medicare } \\
\hline & $\begin{array}{l}\text { Approved } \\
\text { patients } \\
{[\mathrm{A}]} \\
(n=80)\end{array}$ & $\begin{array}{l}\text { Denied } \\
\text { patients } \\
{[\mathrm{B}]} \\
(n=87)\end{array}$ & $\begin{array}{l}\text { Difference } \\
{[A]-[B]}\end{array}$ & $\begin{array}{l}\text { Approved } \\
\text { patients } \\
{[A]} \\
(n=57)\end{array}$ & $\begin{array}{l}\text { Denied } \\
\text { patients } \\
{[\mathrm{B}]} \\
(n=54)\end{array}$ & $\begin{array}{l}\text { Difference } \\
{[\mathrm{A}]-[\mathrm{B}]}\end{array}$ \\
\hline \multicolumn{7}{|l|}{$\begin{array}{l}\text { Condition-specific characteristics } \\
\text { and HCRU }\end{array}$} \\
\hline \multicolumn{7}{|l|}{ MS exacerbation episode } \\
\hline$\geq 1$ exacerbation episode & $21(26.3 \%)$ & $35(40.2 \%)$ & $-14.0 \%$ & $20(35.1 \%)$ & $20(37.0 \%)$ & $-1.9 \%$ \\
\hline $\begin{array}{l}\text { Patients with } 1 \text { exacerbation } \\
\text { episode }\end{array}$ & $18(22.5 \%)$ & $29(33.3 \%)$ & $-10.8 \%$ & $10(17.5 \%)$ & $14(25.9 \%)$ & $-8.4 \%$ \\
\hline $\begin{array}{l}\text { Patients with } 2 \text { exacerbation } \\
\text { episodes }\end{array}$ & $0(0.0 \%)$ & $3(3.4 \%)$ & $-3.4 \%$ & $5(8.8 \%)$ & $4(7.4 \%)$ & $1.4 \%$ \\
\hline $\begin{array}{l}\text { Patients with } \geq 3 \\
\text { exacerbation episodes }\end{array}$ & $3(3.8 \%)$ & $3(3.4 \%)$ & $0.3 \%$ & $5(8.8 \%)$ & $2(3.7 \%)$ & $5.1 \%$ \\
\hline \multicolumn{7}{|l|}{$\begin{array}{l}\text { Neurologic impairment } \\
\text { indicators }\end{array}$} \\
\hline Pain & $15(18.8 \%)$ & $23(26.4 \%)$ & $-7.7 \%$ & $21(36.8 \%)$ & $22(40.7 \%)$ & $-3.9 \%$ \\
\hline Fatigue & $30(37.5 \%)$ & $31(35.6 \%)$ & $1.9 \%$ & $13(22.8 \%)$ & $14(25.9 \%)$ & $-3.1 \%$ \\
\hline Depression & $40(50.0 \%)$ & $38(43.7 \%)$ & $6.3 \%$ & $30(52.6 \%)$ & $33(61.1 \%)$ & $-8.5 \%$ \\
\hline Psychosis & $28(35.0 \%)$ & $30(34.5 \%)$ & $0.5 \%$ & $26(45.6 \%)$ & $21(38.9 \%)$ & $6.7 \%$ \\
\hline Cognitive impairment & $0(0.0 \%)$ & $2(2.3 \%)$ & $-2.3 \%$ & $0(0.0 \%)$ & $3(5.6 \%)$ & $-5.6 \%$ \\
\hline \multicolumn{7}{|l|}{ MS-related treatments } \\
\hline Plasmapheresis & $0(0.0 \%)$ & $0(0.0 \%)$ & $0.0 \%$ & $0(0.0 \%)$ & $1(1.9 \%)$ & $-1.9 \%$ \\
\hline Intravenous immunoglobulin & $1(1.3 \%)$ & $1(1.1 \%)$ & $0.1 \%$ & $0(0.0 \%)$ & $0(0.0 \%)$ & $0.0 \%$ \\
\hline $\begin{array}{l}\text { Other disease-modifying } \\
\text { therapy }\end{array}$ & $35(43.8 \%)$ & $35(40.2 \%)$ & $3.5 \%$ & $26(45.6 \%)$ & $22(40.7 \%)$ & $4.9 \%$ \\
\hline \multicolumn{7}{|l|}{$\begin{array}{l}\text { Rehabilitation and physical } \\
\text { therapy services }\end{array}$} \\
\hline $\begin{array}{l}\text { Patients with } \geq 1 \\
\text { rehab/physical therapy claim }\end{array}$ & $7(8.8 \%)$ & $11(12.6 \%)$ & $-3.9 \%$ & $7(12.3 \%)$ & $6(11.1 \%)$ & $1.2 \%$ \\
\hline $\begin{array}{l}\text { Number of rehab/physical } \\
\text { therapy claims }\end{array}$ & $\begin{array}{l}16.9 \pm 18.8 \\
{[6]}\end{array}$ & $\begin{array}{l}20.2 \pm 21.3 \\
\quad[13]\end{array}$ & -3.32 & $\begin{array}{l}11.3 \pm 17.2 \\
{[3]}\end{array}$ & $\begin{array}{l}18.8 \pm 37.4 \\
{[4]}\end{array}$ & -7.55 \\
\hline \multicolumn{7}{|l|}{ Mobility indicators } \\
\hline Overall & $8(10.0 \%)$ & $14(16.1 \%)$ & $-6.1 \%$ & $12(21.1 \%)$ & $7(13.0 \%)$ & $8.1 \%$ \\
\hline Cane/crutch & $0(0.0 \%)$ & $2(2.3 \%)$ & $-2.3 \%$ & $0(0.0 \%)$ & $0(0.0 \%)$ & $0.0 \%$ \\
\hline
\end{tabular}


Table 4 continued

\begin{tabular}{|c|c|c|c|c|c|c|}
\hline & \multicolumn{3}{|c|}{ Matched MS patients ${ }^{\mathrm{a}}-$ commercial } & \multicolumn{3}{|c|}{ Matched MS patients ${ }^{\mathrm{a}}-$ Medicare } \\
\hline & $\begin{array}{l}\text { Approved } \\
\text { patients } \\
{[A]} \\
(n=80)\end{array}$ & $\begin{array}{l}\text { Denied } \\
\text { patients } \\
{[\mathrm{B}]} \\
(n=87)\end{array}$ & $\begin{array}{l}\text { Difference } \\
{[A]-[B]}\end{array}$ & $\begin{array}{l}\text { Approved } \\
\text { patients } \\
{[A]} \\
(n=57)\end{array}$ & $\begin{array}{l}\text { Denied } \\
\text { patients } \\
{[\mathrm{B}]} \\
(n=54)\end{array}$ & $\begin{array}{l}\text { Difference } \\
{[A]-[B]}\end{array}$ \\
\hline Dalfampridine (Ampyra) & $7(8.8 \%)$ & $8(9.2 \%)$ & $-0.4 \%$ & $12(21.1 \%)$ & $6(11.1 \%)$ & $9.9 \%$ \\
\hline Specialty bed & $0(0.0 \%)$ & $0(0.0 \%)$ & $0.0 \%$ & $0(0.0 \%)$ & $1(1.9 \%)$ & $-1.9 \%$ \\
\hline Walker & $1(1.3 \%)$ & $2(2.3 \%)$ & $-1.0 \%$ & $0(0.0 \%)$ & $0(0.0 \%)$ & $0.0 \%$ \\
\hline Wheelchair & $0(0.0 \%)$ & $2(2.3 \%)$ & $-2.3 \%$ & $0(0.0 \%)$ & $1(1.9 \%)$ & $-1.9 \%$ \\
\hline EDSS-derived disability claims & $\begin{array}{l}2.5 \pm 4.3 \\
{[0]}\end{array}$ & $\begin{array}{l}3.8 \pm 4.7 \\
{[1]}\end{array}$ & -1.29 & $\begin{array}{l}6.6 \pm 8.0 \\
{[3]}\end{array}$ & $\begin{array}{l}7.1 \pm 8.2 \\
{[6]}\end{array}$ & -0.44 \\
\hline \multicolumn{7}{|l|}{ Procedures } \\
\hline MRI & $32(40.0 \%)$ & $34(39.1 \%)$ & $0.9 \%$ & $20(35.1 \%)$ & $14(25.9 \%)$ & $9.2 \%$ \\
\hline \multicolumn{7}{|l|}{ All-cause healthcare resource use } \\
\hline \multicolumn{7}{|l|}{$\geq 1$ visit } \\
\hline Inpatient & $7(8.8 \%)$ & $17(19.5 \%)$ & $-10.8 \%$ & $16(28.1 \%)$ & $18(33.3 \%)$ & $-5.3 \%$ \\
\hline Outpatient/physician office & $72(90.0 \%)$ & $79(90.8 \%)$ & $-0.8 \%$ & $51(89.5 \%)$ & $49(90.7 \%)$ & $-1.3 \%$ \\
\hline Surgery & $0(0.0 \%)$ & $4(4.6 \%)$ & $-4.6 \%$ & $4(7.0 \%)$ & $5(9.3 \%)$ & $-2.2 \%$ \\
\hline Other visits ${ }^{\mathrm{b}}$ & $33(41.3 \%)$ & $41(47.1 \%)$ & $-5.9 \%$ & $30(52.6 \%)$ & $19(35.2 \%)$ & $17.4 \%$ \\
\hline \multicolumn{7}{|l|}{ Visits } \\
\hline Inpatient admissions & $\begin{array}{l}1.4 \pm 0.8 \\
{[1]}\end{array}$ & $\begin{array}{l}1.3 \pm 0.5 \\
{[1]}\end{array}$ & 0.13 & $\begin{array}{l}1.6 \pm 0.9 \\
{[1]}\end{array}$ & $\begin{array}{l}2.2 \pm 1.4 \\
{[2]}\end{array}$ & -0.60 \\
\hline Length of stay (days) & $\begin{array}{l}3.7 \pm 2.8 \\
{[4]}\end{array}$ & $\begin{array}{l}4.9 \pm 7.5 \\
{[3]}\end{array}$ & -1.23 & $\begin{array}{c}4.6 \pm 4.7 \\
{[3]}\end{array}$ & $\begin{array}{l}4.3 \pm 3.5 \\
{[4]}\end{array}$ & 0.29 \\
\hline Surgery & - & - & - & $\begin{array}{l}1.0 \pm 0.0 \\
{[1]}\end{array}$ & $\begin{array}{l}1.4 \pm 0.9 \\
{[1]}\end{array}$ & -0.40 \\
\hline $\begin{array}{l}\text { Outpatient/physician office } \\
\text { visits }\end{array}$ & $\begin{array}{l}8.5 \pm 9.4 \\
{[5]}\end{array}$ & $\begin{array}{l}10.0 \pm 9.8 \\
{[7]}\end{array}$ & -1.51 & $\begin{array}{l}8.6 \pm 8.0 \\
{[5]}\end{array}$ & $\begin{array}{l}8.4 \pm 7.4 \\
{[6]}\end{array}$ & 0.14 \\
\hline Other visits & $\begin{array}{l}3.6 \pm 3.7 \\
{[2]}\end{array}$ & $\begin{array}{l}5.5 \pm 6.0 \\
{[3]}\end{array}$ & -1.90 & $\begin{array}{l}5.5 \pm 5.8 \\
{[3]}\end{array}$ & $\begin{array}{l}10.7 \pm 12.1 \\
{[6]}\end{array}$ & -5.22 \\
\hline $\begin{array}{l}\text { Visits with MS relapse } \\
\text { diagnosis }\end{array}$ & $\begin{array}{l}0.3 \pm 0.7 \\
{[0]}\end{array}$ & $\begin{array}{l}0.6 \pm 1.5 \\
{[0]}\end{array}$ & -0.31 & $\begin{array}{l}0.8 \pm 1.5 \\
\quad[0]\end{array}$ & $\begin{array}{l}0.5 \pm 0.8 \\
\quad[0]\end{array}$ & 0.27 \\
\hline \multicolumn{7}{|l|}{ Prescription drug use } \\
\hline Corticosteroids & $34(42.5 \%)$ & $46(52.9 \%)$ & $-10.4 \%$ & $22(38.6 \%)$ & $21(38.9 \%)$ & $-0.3 \%$ \\
\hline $\begin{array}{l}\text { Average daily corticosteroid } \\
\text { dose }(\mathrm{mg})\end{array}$ & $\begin{array}{l}0.7 \pm 1.9 \\
{[0]}\end{array}$ & $\begin{array}{l}1.6 \pm 4.0 \\
{[0]}\end{array}$ & -0.90 & $\begin{array}{l}0.8 \pm 1.9 \\
{[0]}\end{array}$ & $\begin{array}{l}1.5 \pm 3.7 \\
{[0]}\end{array}$ & -0.63 \\
\hline
\end{tabular}


Table 4 continued

\begin{tabular}{|c|c|c|c|c|c|c|}
\hline & \multicolumn{3}{|c|}{ Matched MS patients ${ }^{\mathrm{a}}-$ commercial $^{2}$} & \multicolumn{3}{|c|}{ Matched MS patients ${ }^{\mathrm{a}}-$ Medicare } \\
\hline & $\begin{array}{l}\text { Approved } \\
\text { patients } \\
{[\mathbf{A}]} \\
(n=80)\end{array}$ & $\begin{array}{l}\text { Denied } \\
\text { patients } \\
{[B]} \\
(n=87)\end{array}$ & $\begin{array}{l}\text { Difference } \\
{[\mathrm{A}]-[\mathrm{B}]}\end{array}$ & $\begin{array}{l}\text { Approved } \\
\text { patients } \\
{[A]} \\
(n=57)\end{array}$ & $\begin{array}{l}\text { Denied } \\
\text { patients } \\
{[B]} \\
(n=54)\end{array}$ & $\begin{array}{l}\text { Difference } \\
{[\mathrm{A}]-[\mathrm{B}]}\end{array}$ \\
\hline Number of prescriptions filled & $\begin{array}{c}38.9 \pm 25.5 \\
{[35]}\end{array}$ & $\begin{array}{c}41.3 \pm 31.4 \\
{[35]}\end{array}$ & -2.35 & $\begin{array}{c}59.9 \pm 49.2 \\
{[53]}\end{array}$ & $\begin{array}{c}60.8 \pm 56.9 \\
{[37]}\end{array}$ & -0.96 \\
\hline Number of unique drugs & $\begin{array}{c}16.7 \pm 8.4 \\
{[16]}\end{array}$ & $\begin{array}{c}15.9 \pm 10.9 \\
{[14]}\end{array}$ & 0.85 & $\begin{array}{c}20.7 \pm 14.5 \\
{[17]}\end{array}$ & $\begin{array}{c}20.2 \pm 15.8 \\
{[14]}\end{array}$ & 0.46 \\
\hline
\end{tabular}

$H C R U$ healthcare resource utilization, SD standard deviation, EDSS Expanded Disability Status Scale

a Denied patients are propensity score matched $\left( \pm \frac{1 / 4}{4} \mathrm{SD}\right)$ 1:1 to approved patients. The matching criteria include all baseline characteristics reported in the baseline tables

b The Symphony data list all visits that are not inpatient, outpatient, or surgery as "other"

for MS relapse using a uniquely suited database. As a result, the findings of this study may help providers and health plans review current situations in which RCI treatment may be beneficial to further improve quality of care and potentially improve outcomes, particularly among MS patients who do not respond to or are unable to tolerate first-line therapies such as high-dose CS. The results of this real-world study, indicating that RCI treatment for MS relapse may be associated with a number of improved patient outcomes, underlines the importance of continued access to alternative therapies in this important patient population.

\section{ACKNOWLEDGEMENTS}

Funding. Sponsorship of this study and the journal's rapid service fee were funded by Mallinckrodt Pharmaceuticals (Bedminster, NJ).

Authorship. All named authors meet the International Committee of Medical Journal Editors (ICMJE) criteria for authorship for this article, take responsibility for the integrity of the work as a whole, and have given their approval for this version to be published.
Disclosures. John Niewoehner and George J. Wan are employees of Mallinckrodt Pharmaceuticals, which provided research funding to Analysis Group (employer of J. Bradford Rice, Alan White, Mark Simes, Emma Billmyer, and Nathaniel Downes). Mary P. Panaccio is a paid consultant for Mallinckrodt Pharmaceuticals.

Compliance with Ethics Guidelines. Because of the nature of the retrospective study design using previously collected, de-identified data, institutional review board (IRB) approval was not necessary for this study.

Data Availability. The data sets generated during and/or analyzed during the current study are not publicly available because they are proprietary administrative health claims data owned by Symphony Health.

Open Access. This article is licensed under a Creative Commons Attribution-NonCommercial 4.0 International License, which permits any non-commercial use, sharing, adaptation, distribution and reproduction in any medium or format, as long as you give appropriate credit to the original author(s) and the source, provide a link to the Creative Commons licence, and indicate if changes were made. The images or other third party material in this article are 
included in the article's Creative Commons licence, unless indicated otherwise in a credit line to the material. If material is not included in the article's Creative Commons licence and your intended use is not permitted by statutory regulation or exceeds the permitted use, you will need to obtain permission directly from the copyright holder. To view a copy of this licence, visit http://creativecommons.org/licenses/by$\mathrm{nc} / 4.0 /$.

\section{REFERENCES}

1. Wallin MT, Culpepper WJ, Campbell JD, et al. The prevalence of MS in the United States. Neurology. 2019;92(10):e1029-40. https://doi.org/10.1212/ wnl.0000000000007035.

2. Goodin DS, Frohman EM, Garmany GP Jr, et al. Disease modifying therapies in multiple sclerosis: report of the Therapeutics and Technology Assessment Subcommittee of the American Academy of Neurology and the MS Council for Clinical Practice Guidelines. Neurology. 2002;58(2):169-78. https:// doi.org/10.1212/wnl.58.2.169.

3. Nazareth T, Rava AR, Polyakov JL, et al. Relapse prevalence, symptoms, and health care engagement: patient insights from the Multiple Sclerosis in America 2017 survey. Multiple sclerosis and related disorders. 2018;26:219-34. https://doi.org/ 10.1016/j.msard.2018.09.002.

4. Types of MS National Multiple Sclerosis Society; 2020. https://www.nationalmssociety.org/What-isMS/Types-of-MS. Accessed 19 June 2020.

5. Ohlmeier C, Gothe H, Haas J, et al. Epidemiology, characteristics and treatment of patients with relapsing remitting multiple sclerosis and incidence of high disease activity: real world evidence based on German claims data. PLoS ONE. 2020;15(5): e0231846. https://doi.org/10.1371/journal.pone. 0231846.

6. Relapse Management: National Multiple Sclerosis Society; 2020 [cited 2020 June 19]. https://www. nationalmssociety.org/Treating-MS/ManagingRelapses.

7. Liu S, Liu X, Chen S, et al. Oral versus intravenous methylprednisolone for the treatment of multiple sclerosis relapses: a meta-analysis of randomized controlled trials. PLoS One. 2017;12(11):e0188644. https://doi.org/10.1371/journal.pone.0188644.
8. Burton JM, O'Connor PW, Hohol M, et al. Oral versus intravenous steroids for treatment of relapses in multiple sclerosis. Cochrane Datab Syst Rev 2009;8(3):Cd006921. https://doi.org/10.1002/ 14651858.cd006921.pub2.

9. Rice JB, White AG, Johnson M, et al. Quantitative characterization of the relationship between levels of extended corticosteroid use and related adverse events in a US population. Curr Med Res Opin. 2018;34(8):1519-27. https://doi.org/10.1080/ 03007995.2018 .1474090 .

10. Rice JB, White AG, Johnson M, et al. Healthcare resource use and cost associated with varying dosages of extended corticosteroid exposure in a US population. J Med Econ. 2018;21(9):846-52. https://doi.org/10.1080/13696998.2018.1474750.

11. Rice JB, White AG, Scarpati LM, et al. Long-term systemic corticosteroid exposure: a systematic literature review. Clin Ther. 2017;39(11):2216-29. https://doi.org/10.1016/j.clinthera.2017.09.011.

12. Treating multiple sclerosis relapses: multiple sclerosis Association of America; 2020 [cited 2020 June 19]. http://www.mymsaa.org/ms-information/ treatments/relapses.

13. Elovaara I, Kuusisto $\mathrm{H}, \mathrm{Wu} \mathrm{X}$, et al. Intravenous immunoglobulins are a therapeutic option in the treatment of multiple sclerosis relapse. Clin Neuropharmacol. 2011;34(2):84-9. https://doi.org/10. 1097/WNF.0b013e31820a17f3.

14. Acthar Prescribing Information: Mallinckrodt Pharmaceuticals 2019 [cited 2020 June 19]. Available from: https://www.acthar.com/pdf/Acthar-PI. pdf.

15. Rose A, Kuzma JW, Kurtzke JF, et al. Cooperative study in the evaluation of therapy in multiple sclerosis: ACTH vs. placebo-final report. Neurology. 1970;20(5 Part 2):1-59. https://doi.org/10. 1212/wnl.20.5_part_2.1.

16. Simsarian JP, Saunders C, Smith DM. Five-day regimen of intramuscular or subcutaneous self-administered adrenocorticotropic hormone gel for acute exacerbations of multiple sclerosis: a prospective, randomized, open-label pilot trial. Drug Des Dev Ther. 2011;5:381-9. https://doi.org/ 10.2147/dddt.S19331.

17. Damal K, Stoker E, Foley JF. Optimizing therapeutics in the management of patients with multiple sclerosis: a review of drug efficacy, dosing, and mechanisms of action. Biol Targ Ther. 2013;7: 247-58. https://doi.org/10.2147/btt.S53007.

18. Kunker KA, Drake AS, Irwin LN, et al. Cognitive changes in multiple sclerosis patients treated with 
subcutaneous adrenocorticotropic hormone for acute relapse [Abstract P1111]. ECTRIMS Online Library. 2016.

19. Nazareth T, Datar M, Sheer R, et al. MS relapse treatments and relapse resolution: retrospective study results from a US health plan [ECTRIMSACTRIMS poster P809]. ECTRIMS Online Library. 2017.

20. Nazareth T, Datar M, Yu TC. Treatment effectiveness for resolution of multiple sclerosis relapse in a US Health Plan Population. Neurol Ther. 2019;8(2): 383-95. https://doi.org/10.1007/s40120-01900156-5.

21. Nazareth T, Datar M, Schwab P, et al. Relapse resolution and HCRU in patients with multiple sclerosis: a retrospective study of relapse therapy alternatives to corticosteroids [ECTRIMS-ACTRIMS poster EP1425]. ECTRIMS Online Library. 2017.

22. Gold LS, Suh K, Schepman PB, et al. Healthcare costs and resource utilization in patients with multiple sclerosis relapses treated with H.P. Acthar Gel $\left({ }^{\circledR}\right)$. Adv Ther. 2016;33(8):1279-92. https://doi. org/10.1007/s12325-016-0363-0.

23. Costello J, Njue A, Lyall M, et al. Efficacy, safety, and quality-of-life of treatments for acute relapses of multiple sclerosis: results from a literature review of randomized controlled trials. Degener Neurol Neuromuscul Dis. 2019;9:55-78. https://doi.org/10. 2147/dnnd.S208815.

24. Chastek BJ, Oleen-Burkey M, Lopez-Bresnahan MV. Medical chart validation of an algorithm for identifying multiple sclerosis relapse in healthcare claims. J Med Econ. 2010;13(4):618-25. https://doi. org/10.3111/13696998.2010.523670.

25. Ollendorf DA, Jilinskaia E, Oleen-Burkey M. Clinical and economic impact of glatiramer acetate versus beta interferon therapy among patients with multiple sclerosis in a managed care population. JMCP. 2002;8(6):469-76. https://doi.org/10.18553/ jmcp.2002.8.6.469.

26. Austin PC. An introduction to propensity score methods for reducing the effects of confounding in observational studies. Multivar Behav Res. 2011;46(3):399-424. https://doi.org/10.1080/ 00273171.2011 .568786 .

27. Quan H, Sundararajan V, Halfon P, et al. Coding algorithms for defining comorbidities in ICD-9-CM and ICD-10 administrative data. Med Care. 2005;43(11):1130-9. https://doi.org/10.1097/01. mlr.0000182534.19832.83.

28. Pyenson B, Tomicki S. Multiple sclerosis: new perspectives on the patient journey: Milliman Client Report; 2019 [cited 2020 June 19]. https://us. milliman.com/en/insight/multiple-sclerosis-newperspectives-on-the-patient-journey-2019-update.

29. Kurtzke JF. Rating neurologic impairment in multiple sclerosis: an expanded disability status scale (EDSS). Neurology. 1983;33(11):1444-52. https:// doi.org/10.1212/wnl.33.11.1444.

30. Multiple Sclerosis Quality Measurement Set: American Academy of Neurology; 2014 [cited 2020 June 19]. https://www.aan.com/siteassets/home-page/ policy-and-guidelines/quality/quality-measures/ 14msmeasureset_pg.pdf.

31. Rae-Grant A, Bennett A, Sanders AE, et al. Quality improvement in neurology: multiple sclerosis quality measures: executive summary. Neurology. 2015;85(21):1904-8. https://doi.org/10.1212/wnl. 0000000000001965 .

32. Shoemaker SJ, Pozniak A, Hadden L. Assessing four quality indicators for multiple sclerosis management through patient-reported data. Int J MS Care. 2016;18(4):202-9. https://doi.org/10.7224/15372073.2014-097. 